\title{
PARAMETRIC COMPARISON OF RECTANGULAR AND CIRCULAR PONTOONS PERFORMANCE AS FLOATING BREAKWATER NUMERICALLY
}

\author{
Seyyed Mohammad Reza Tabatabaei \\ Hamid Zeraatgar \\ Amirkabir University of Technology, Tehran, Iran
}

\begin{abstract}
Rectangular and circular pontoons are one of the most widely cross-sections used as floating breakwaters (FB). Although, there are several articles on comparison of behavior of rectangular and circular floating breakwaters however, the Authors try to show some details of difference between these two types where they have not been addressed before. To do so, transmission coefficient (Ct), as a measure of merit, of similar rectangular and circular sections is numerically compared. A computer code is developed for two-dimensional hydrodynamic analysis of floating breakwater based on diffraction theory in frequency domain in regular waves with any configuration of mooring line. The numerical method is the finite element method and validated by comparing with experimental and numerical results. Three types of rectangular sections are defined equivalent to circular section and a numerical comparison is made between 100 similar sections. The Ct versus wave frequency has been considered in detail and three new points called LMinF, LMaxF and LMaxCt are introduced. It has been shown that LMinF and LMaxF of circular section are greater and LMaxCt is much smaller than equivalent rectangular section. The LMaxCt of both sections are very dependent to new nondimensional parameter B/D (Breadth/Draft). Although, rectangular sections are more common for floating breakwater, however the results of this study show that possibility of using circular sections must be also considered.
\end{abstract}

Keywords: Floating Breakwater, transmission coefficient, circular section, rectangular section,

\section{INTRODUCTION}

For many years, fixed breakwaters have been used to create a calm environment for different purposes such as loading, unloading, fishing, military and even recreational use. They were designed and implemented vertically or sloped. Rubble mound breakwaters are the most common type of sloped fixed breakwaters that is built with stone pouring from the sea floor to above water level. For various reasons, such as high cost especially in deep water, extreme sedimentation, poor sea bed and large changes in water level because of tide, floating breakwater (FB) was introduced.

Sea wave energy is mainly distributed on water surface. Therefore it is not necessary to extend breakwaters up to sea bed, especially in deep water condition. The FB is a floating structure on water surface and its movements are limited by mooring lines. As a system of sea wave hits a FB, it responses by motion in six degrees of freedom, that is surge, sway, heave, roll, pitch and yaw. A FB response depends on its specifications such as, geometry, mass and its distribution and incident wave parameters such as period and height. Additionally, the FB motions in wave are function of mooring characteristics such as material, weight, length, angle and its type. All six motions may have a natural frequency and they can be determined by breakwater geometrical characteristics and mooring line specifications.

Normally, the extreme motions of a FB may happen when direction of wave propagation is perpendicular to 
the longitudinal axis of the FB. In this case, the motion is limited to the sway, heave and roll and they are coupled to each other. Since, in areas near beach, waves usually propagate perpendicular to the breakwater, thus two-dimensional analysis of FB is realized.

In the past few decades, numerous analytical, experimental and numerical studies have been done, mainly to increase performance and reduce costs of FB. (McCartney, 1985; Mani, 1991) categorized types of FB based on their specifications and expressed the advantages and disadvantages of each type. On that basis, FB types are pontoon, mat and tethered.

The most common type of FB is rectangular section, Ji (2015), due to the ease of production and transportation as well as the flat deck. The other common pontoon sections are circular and trapezoidal, Sawaragi (1995). So far, plenty of researches have been directed to the rectangular pontoon but there is still a lack of enough information on circular sections, Ozeren (2011).

Bloomberg (1998) compared Ct of seven types of rectangular sections and concluded that the catamaran type has the best performance. The types that he considered include single, double, triple, double with 1, 2, 4 meter intermediate skirt and catamaran.

Dimer et al. (1992) analytically investigated 2-D pontoon type of FB in regular wave. They have shown that at intermediate water depth, the pontoon type FB has well performance against wave with wave lengths several times of width of the structures.

Sannasiraj et al. (1998) made a two-dimensional experiment as well as numerical calculation on a rectangular pontoon having three mooring configurations. They measured and calculated motion responses such as sway, heave, roll, $\mathrm{Ct}$ and mooring forces. Results showed that numerical code written by finite element method is pretty reliable to predict FB behavior. They concluded that changing type of mooring configuration does not make a significant difference on $\mathrm{FB}$ performances.

Behzad et al. (2007) experimentally investigated response and efficiency of five types of pontoon with different drafts in random waves. It was shown that by increasing the wave period the Ct increases, while increase of the mass reduces the Ct.

Mays (1998) summarized works done on the circular cylinder in his $\mathrm{PhD}$ thesis. He examined submerged circular cylinder encountering sea waves in oblique and perpendicular directions by a three-dimensional numerical boundary element method. It was shown that circular section is efficient for a wide range of wave directions.

Ozeren et al. (2011) studied single and multiple circular sections with three types of mooring line namely bottommoored, arm-restrained and pile-restrained in deep and transitional water depth. It was shown that in pile-restrained type, wave reflection was much more than two other types. Additionally, for the pile-restrained type, performance depends on section draft to height ratio. Moreover, for the two other types of mooring line, dissipation had the greatest influence on Ct. Besides, in order to improve performance of $\mathrm{FB}$, the horizontal restraint is more important than the vertical one.

Isaacson et al. (1995) studied circular sections with chain and nylon mooring line in regular waves, experimentally. It was stated that for $\mathrm{Ct}$, the breadth ratio i.e. diameter of cylinder to wavelength will be more effective than wave steepness. The Authors must indicate that this is the only study in which rectangular and circular sections are compared, experimentally. They concluded that the circular and rectangular sections have similar responses where $\mathrm{Ct}$ of rectangular section is slightly less than circular section. Moreover, they stated that the concrete circular pontoons have less cost, torsion and tension in corners compared with rectangular one due to wave impact.

Shankar (1998) in his PhD thesis, numerically studied two similar pontoons connected to each other where one had rectangular section and the other had circular section. As far as $\mathrm{Ct}$ is concerned, it was shown that the size of pontoon and pontoon's breadth are the most important parameters. They also stated that circular section behaves like rectangular section very much.

Although, there are several articles on comparison of behavior of rectangular and circular FB however, the Authors try to show some details of difference between these two types where they have not been addressed before. To do so, the Ct of 100 similar rectangular and circular sections is numerically compared. A computer code is developed for two-dimensional hydrodynamic analysis of FB based on diffraction theory in frequency domain in regular waves with any configuration of mooring line. The numerical method is the finite element method and validated by comparing with experimental and numerical researches. A parametric study for comparison of these two sections is carried out. It has been shown that generally circular section has better transmission coefficient.

\section{THEORY AND BASIC EQUATIONS}

Fig.1 shows a FB with mooring line. A coordinate system is defined where its origin is located on symmetry line of the $\mathrm{FB}$ and waterline. The $\mathrm{x}$ and $\mathrm{y}$ are on water surface and $\mathrm{z}$ is perpendicular to the water surface.

The fluid is assumed to be ideal, incompressible and irrotational, and therefore the governing equation is the Laplace equation.

$$
\nabla . \nabla \varphi=0 \rightarrow \nabla^{2} \varphi=0 \rightarrow \frac{\partial^{2} \varphi}{\partial x^{2}}+\frac{\partial^{2} \varphi}{\partial y^{2}}+\frac{\partial^{2} \varphi}{\partial z^{2}}=0
$$

Where $\varphi$ is the velocity potential, $x, y$ and $z$ are spatial variables. Wave height and motion assumed to be small. The FB dimensions in respect to wavelength are large where use of diffraction theory is justified.

As shown in Fig .1 the dynamic of the FB is defined as a twodimensional problem where four different configurations of symmetrical catenaries mooring lines are considered. 


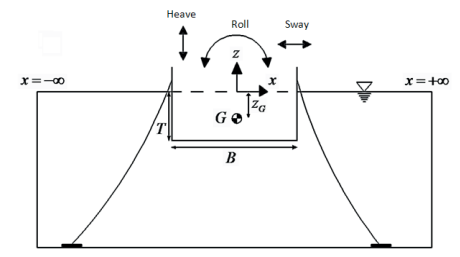

Fig. 1. FB, motions, degrees of freedom and position of coordinate axes

In order to solve the equation (1) the boundary conditions are to be defined according to physical conditions of the problem. Boundary condition on the surface of the rigid body is defined as follows:

$$
\nabla \varphi \cdot \hat{n}=\frac{\partial \varphi}{\partial n}=V_{B} \cdot \hat{n}=V_{B n}
$$

Where $\hat{n}$ is the unit vector normal to the body surface, $V_{\mathrm{B}}$ is velocity of the body at the desired point and $V_{\mathrm{Bn}}$ is the component of velocity normal to the surface.

Impermeable boundary of sea bed will be as follows:

$$
\left.\frac{\partial \varphi}{\partial z}\right|_{z=-h}=0
$$

Linear boundary condition of free surface is defined as follows:

$$
\frac{\partial^{2} \varphi}{\partial t^{2}}+g \frac{\partial \varphi}{\partial z}=0
$$

Far field boundary condition is:

$$
\frac{\partial \varphi_{s}}{\partial r}+\frac{1}{c} \frac{\partial \varphi_{s}}{\partial t}=0
$$

Where $\varphi_{s}$ is velocity potential for scattered wave due to floating body, and $\mathrm{c}$ is the wave celerity and $\mathrm{r}$ is the radial distance from the desired point on the surface of the body.

The linear diffraction is applicable when wave height and response of the body are small. The total velocity potential can be written in terms of its components as follow:

$$
\varphi(x, z, t)=\varphi_{I}(x, z, t)+\varphi_{D}(x, z, t)+\varphi_{R}(x, z, t)
$$

Where:

$\varphi_{I}(x, z, t)$ Is velocity potential of incident wave $\varphi_{D}(x, z, t)$ Is velocity potential of diffraction due to floating body

$\varphi_{R}(x, z, t)$ Is velocity potential of radiated energy due to motions of floating body

Having assumed a sinusoidal regular wave as incident wave, there is an analytical solution for incident wave velocity potential. The diffraction and radiation velocity potentials are obtained by solving boundary value problems, numerically. Having used Bernoulli equation, one may calculate the pressure on the FB. In order to calculate the forces acting on the $\mathrm{FB}$, it is necessary to integrate the pressure exerted on the wetted surface. By implementing Newton's second law, motion of FB could be extracted from the equation of motion.

The equation of motion, boundary condition, boundary value problems and quasi-static analysis of mooring line based on basic catenary equations is fully described by Sannasiraj et all. (1998)

\section{COMPUTER CODE AND VALIDATION}

\section{COMPUTER CODE}

To analyze the motions of FB in waves, a computer code based on FEM model is developed in MATLAB. Input data are water depth, breadth or diameter of FB, draft, wave frequency range and frequency increment. For each wave frequency, zone of the problem is defined, mesh is generated and velocity potential for each node is calculated. The zone of the problem is set as twice the wavelength plus breakwater breadth. After calculation of pressure, motion amplitude of three degrees of freedom, response amplitude operator and $\mathrm{Ct}$ is calculated. The code is able to analyze any geometry of FB. Fig. 2 shows flowchart of the computer code.

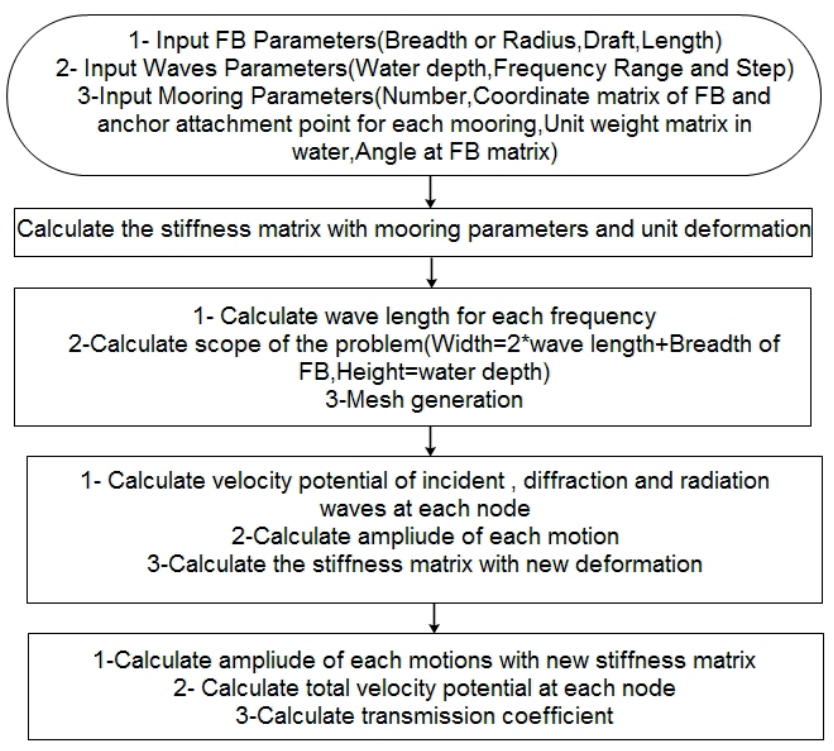

Fig. 2. Flowchart of the computer code

\section{VALIDATION}

In order to validate the computer code, two cross sections, rectangular and circular, for which experimental results have been published, are considered. 


\section{Rectangular pontoon}

As mentioned previously, Sannasiraj et al. (1998) studied rectangular pontoons, experimentally and numerically. The experiment performed in constant water depth of $2.35 \mathrm{~m}$, catenary chain mooring with fixed length of $4.7 \mathrm{~m}$ and weight of $1.25 \mathrm{~N} / \mathrm{m}$, wave with $0.05 \mathrm{~mm}$ height and 0.3 to $1.5 \mathrm{~Hz}$ frequency range propagating perpendicular to the longitudinal axis of the breakwater. The Sannasiraj et al. model experiment has been widely used for validation of numerical models due to publishing many details of test parameters. The Sannasiraj et al. rectangular pontoon parameters and three symmetrical mooring line configurations called $\mathrm{C} 1$, C2 and C3 are shown in Table 1 and Fig. 3.

Tab1. Sannasiraj et al. (1998), rectangular pontoon specifications

\begin{tabular}{|l|c|c|c|}
\hline \multicolumn{1}{|c|}{ Particulars } & Symbol & Unit & Value \\
\hline Length & $\mathrm{L}$ & $\mathrm{M}$ & 3.78 \\
\hline Breadth & $\mathrm{B}$ & $\mathrm{M}$ & 0.40 \\
\hline Draft & $\mathrm{T}$ & $\mathrm{M}$ & 0.10 \\
\hline Mass & $\mathrm{M}$ & $\mathrm{Kg}$ & 150.5 \\
\hline Mass center & $\left(\mathrm{X}_{\mathrm{g}}, \mathrm{Z}_{\mathrm{g}}\right)$ & $\mathrm{M}$ & $(0.0,0.026)$ \\
\hline Transverse Metacentric height & $\mathrm{GM}_{\mathrm{T}}$ & $\mathrm{M}$ & 0.057 \\
\hline Mass MI about transverse axis & $\mathrm{I}_{\mathrm{xx}}$ & $\mathrm{kg} \mathrm{m}{ }^{2}$ & 188.0 \\
\hline Mass MI about longitudinal axis & $\mathrm{I}_{\mathrm{yy}}$ & $\mathrm{kg} \mathrm{m}^{2}$ & 5.33 \\
\hline Mass MI about vertical axis & $\mathrm{I}_{\mathrm{zz}}$ & $\mathrm{kg} \mathrm{m}^{2}$ & 189.8 \\
\hline Roll natural frequency & $\mathrm{f}_{\mathrm{r}}$ & $\mathrm{Hz}_{\mathrm{z}}$ & 0.592 \\
\hline Heave natural frequency & $\mathrm{f}_{\mathrm{z}}$ & $\mathrm{Hz}$ & 1.012 \\
\hline
\end{tabular}

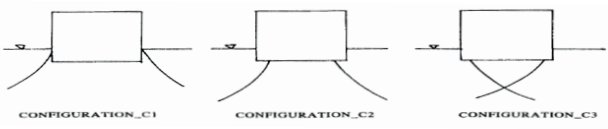

Fig. 3. Sannasiraj et al. (1998), rectangular pontoon and three mooring line configurations

In the case of $\mathrm{C} 1$ mooring configuration, the $\mathrm{RAO}$ of sway, heave and roll motions and Ct of Sannasiraj et al. experiment as well as numerical model and present study are shown in Figs. 4 to 7, respectively. Generally, the present study follows the trend of experiment for three motions as well as for transmission coefficient. However, there is some considerable difference between the present method and experiment for some frequencies. More or less this difference is repeated in Sannasiraj et al. numerical method, too. At natural frequency of roll motion that is $0.592 \mathrm{~Hz}$ or 0.2712 in non-dimensional form, the present method has shown better compliance with experiment both for motions and $\mathrm{Ct}$ in comparison with the Sannasiraj et al. numerical method. One may aware of uncertainty of experiment in particular at natural frequency as two $\mathrm{Ct}$ for a single frequency are reported.

Fig.7 also shows that, at the roll natural frequency, waves generated by FB has significantly decreased the Ct.

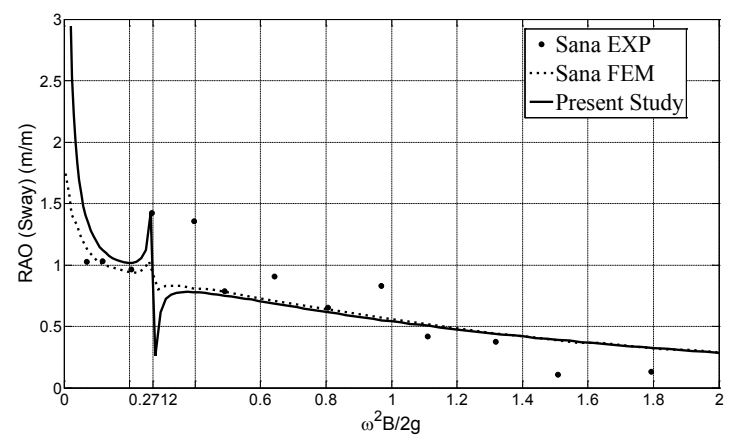

Fig. 4. Comparison RAO of sway motion, C1 mooring configuration

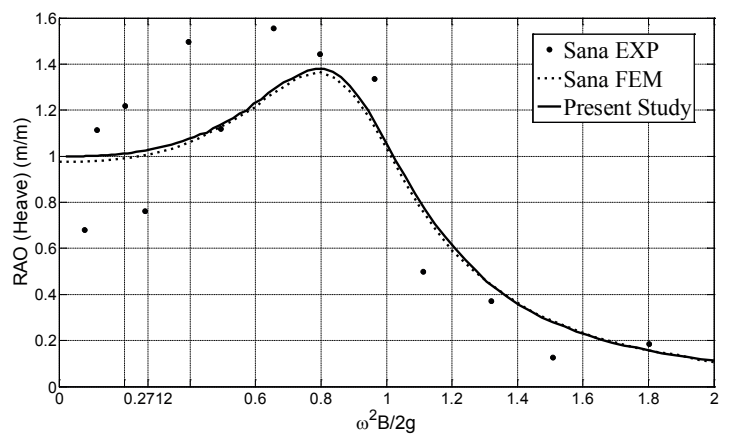

Fig. 5. Comparison of RAO of heave motion, C1 mooring configuration

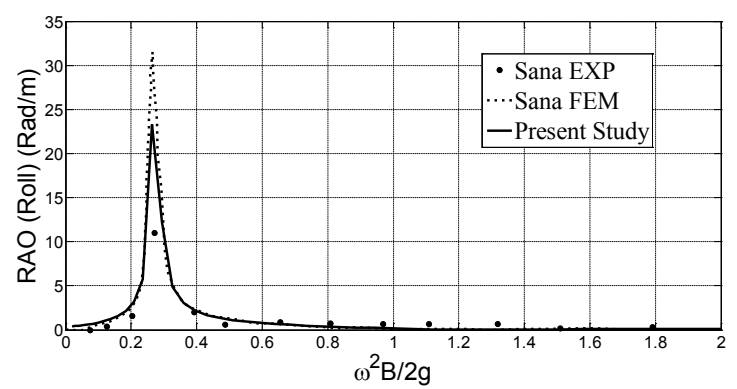

Fig. 6. Comparison of RAO of roll motion, C1 mooring configuration

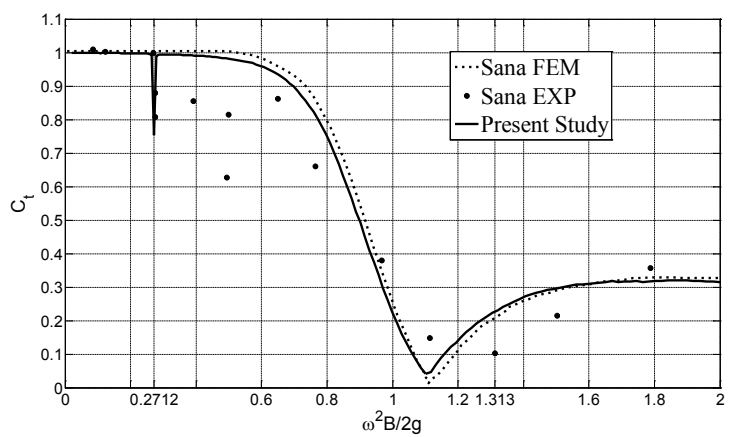

Fig. 7. Ct comparison for C1 mooring configuration

In the case of $\mathrm{C} 2$ mooring configuration, the RAO of sway, heave and roll motions of Sannasiraj et al. (1998) experiment and numerical model, Lee and Cho (2003) numerical elementfree Galerkin model and Loukogeorgaki et al. (2005 a, b) 3-D panel method are compared with the present study as shown 
in Figures 8 to 10. It is worth to mention that Loukogeorgaki et al. used Green's theorem, panel method and static and dynamic analysis of mooring with iteration method. Basically, the present study follows the trend of experiment for three motions. However, there is some difference between present method and experiment for some frequencies. More or less this difference is repeated in other numerical methods, too.

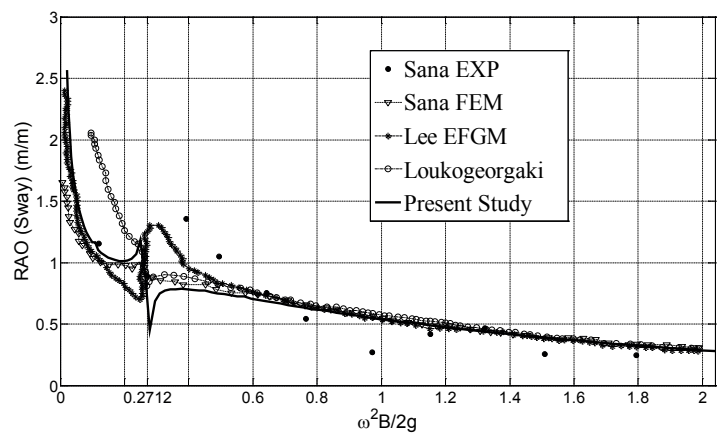

Fig. 8. Comparison of RAO of sway motion, C2 mooring configuration

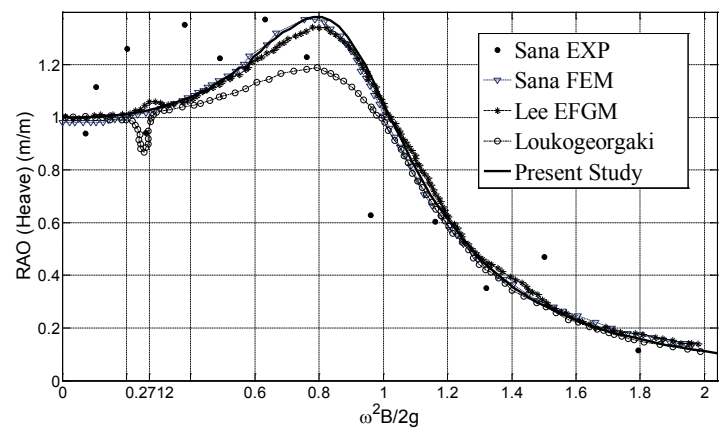

Fig. 9. Comparison of RAO of heave motion, C2 mooring configuration

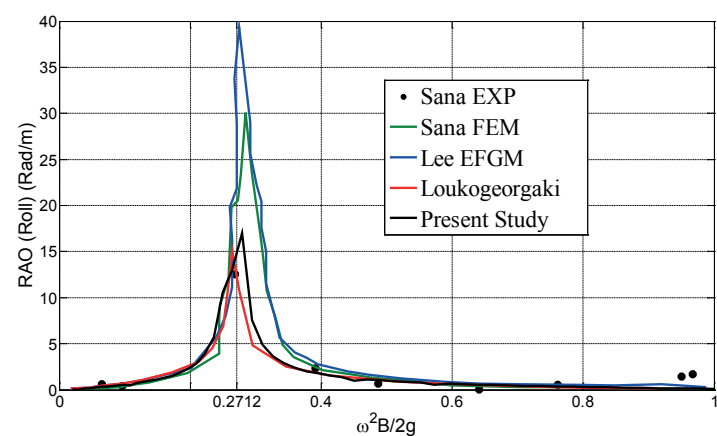

Fig. 10 Comparison of RAO of roll motion, C2 mooring configuration

Fig. 8 shows that for sway motion, all numerical studies follow the same trend as experimental results.

Fig. 9 shows that Loukogeorgaki et al., in some frequency in particular at natural frequency of rolling, better predicts the heave amplitude, but in other frequencies is worse.
As Fig. 10 shows, results of present study at the roll natural frequency are quite better than others in comparison with experiment.

\section{Circular pontoon}

Isaacson et al. (1995) provided 2D and 3D experiments and 2D numerical calculation for circular pontoon with different mooring configurations. As depicted in Fig.11, the moorings are chain and nylon types and connected to the pontoon in three configurations called bottom, crossed and uncrossed.

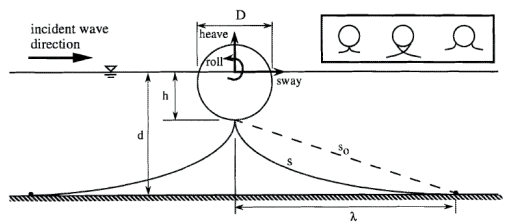

Fig. 11. Circular pontoon cross-section and three mooring configurations, Isaacson et al. (1995)

In $2 \mathrm{D}$ experimental study of Isaacson that is called Wave Flume Test, the flume parameters are $0.62 \mathrm{~m}$ width, $40 \mathrm{~m}$ length and $0.6 \mathrm{~m}$ water depth. A PVC model of $321 \mathrm{~mm}$ diameter, $0.62 \mathrm{~m}$ length, slightly smaller than the width of the flume, manufactured and for several $\mathrm{h} / \mathrm{D}$ and draught to diameter had been tested. In the case of bottom chain mooring configuration with $\mathrm{S} / \mathrm{S} 0=1.060,140 \mathrm{~N} / \mathrm{m}$ submerged weight and $\mathrm{h} / \mathrm{D}=0.579$, the $\mathrm{Ct}$ and the $\mathrm{RAO}$ of sway, heave and roll are calculated by present method and compared with Isaacson as shown in Figs. 12 to 15, respectively.

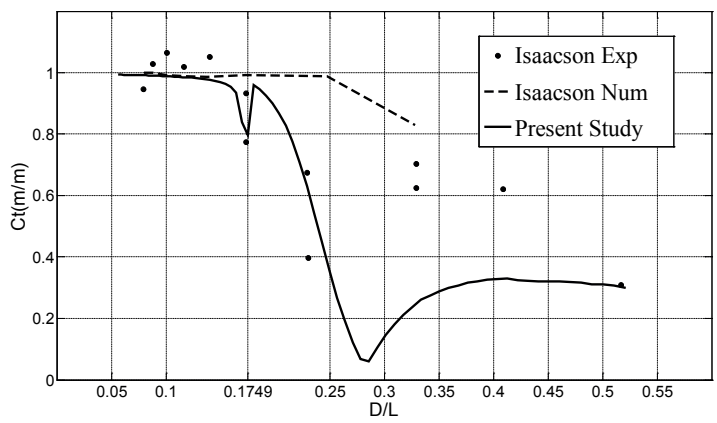

Fig. 12. Ct comparison of circular pontoon, chain moored at bottom of pontoon

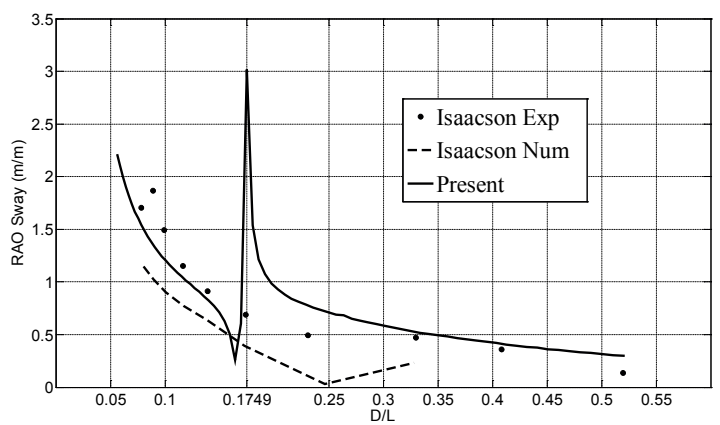

Fig. 13. Comparison of RAO of sway motion of circular pontoon, chain moored at bottom of pontoon 


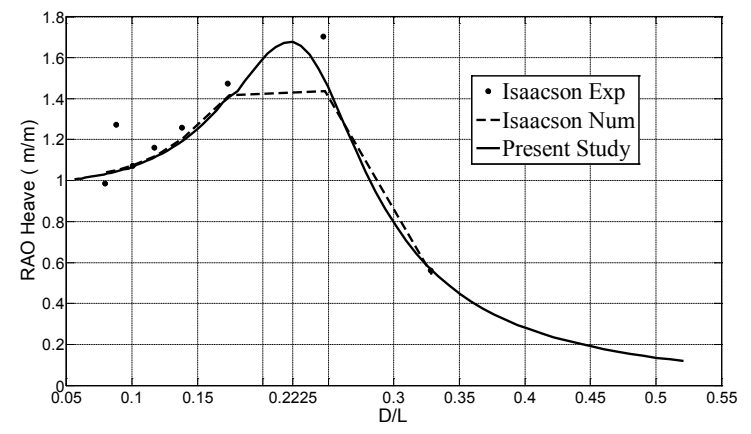

Fig. 14. Comparison of RAO of heave motion of circular pontoon, chain moored at bottom of pontoon

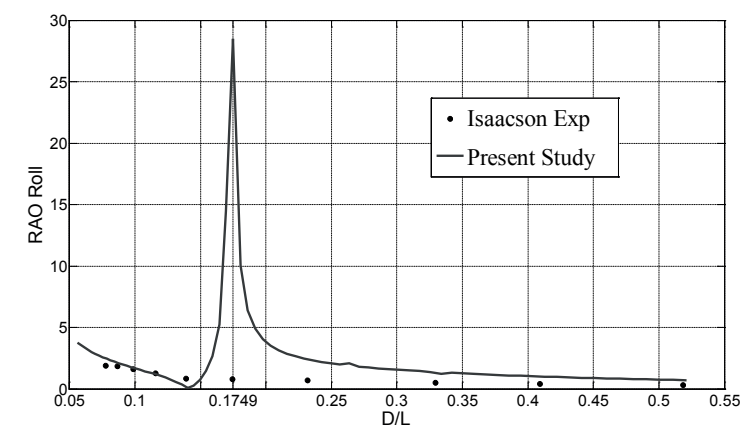

Fig. 15. Comparison of RAO of roll motion of circular pontoon, chain moored at bottom

Fig.12 shows that, in general, the present study follows the $\mathrm{Ct}$ trend as in experiment. However, there is significant underestimation for the $\mathrm{D} / \mathrm{L}$ ranging of 0.30 to 0.40 . Furthermore, the Ct trend changes sharply around $\mathrm{D} / \mathrm{L}=0.3$. Besides, a very good compliance with the experiment at resonance frequency is quite promising. One may conclude that the present study is complying with the experiment better than the Isaacson numerical method.

Fig.13 shows that, for sway motion, the present numerical method follows the same trend of experiment except at resonance frequency. As far as roll motion is concerned, the present method depicts the same tendency as shown in Figure 15. Since, the sway and roll motions are strongly coupled, the deviance from experiment at roll resonance frequency for both motions are more pronounced. It may arise from viscous damping which is not included in the present method.

The heave motion is uncoupled to the roll and sway motions. That is why, according to Figure 14, a pretty good prediction of heave motion for all range of $\mathrm{D} / \mathrm{L}$ in respect to experiment achieved. General speaking, the present method seems to predict the experiment better than the Isaacson numerical method.

Having considered the above validation studies, one may conclude that the present method is an accepted tool to be used for analysis of moored FB with different sections.

\section{A PARAMETRIC STUDY ON COMPARISON OF RECTANGULAR AND CIRCULAR FB}

There are several studies comparing effectiveness of circular FB with the rectangular FB such as Isaacson et al. (1995) and Shunkar (1998). However, this study tries to present more comprehensive comparison between these two sections at fair conditions.

Certainly, the rectangular section in comparison with circular section is easy to be manufactured and also better for operation as it provides flat deck. If these two sections are to be compared on the basis of their hydrodynamic performance, the transmission coefficient is the best measure of merit.

\section{DEFINITION OF SIMILAR CIRCULAR AND RECTANGULAR SECTIONS}

In order to compare the performance of circular and rectangular sections, the size of them is to be similar to ensure a fair comparison. The similar size of two sections may be defined by three ways:

Type I: rectangular section with the same breadth and draft of circular section, but different buoyancy

$$
\begin{aligned}
& 2 * R_{C}=\text { Breadth }_{R}=\text { Breadth }_{c} \\
& R_{C}=\text { draft }_{R}=\text { Draft }_{c} \\
& A_{C}=\left(\pi R_{C}^{2}\right) / 2 \\
& A_{R}=\text { Breadth }_{R} * \text { Draft }_{R}=2 * R_{C}^{2}>A_{C}
\end{aligned}
$$

Type II: rectangular section with the same breadth and buoyancy of circular section, but different draft

$$
\begin{aligned}
& A_{C}=A_{R}=\left(\pi R_{C}{ }^{2}\right) / 2=\text { Breadh }_{R} * \text { Draft }_{R} \\
& \text { Breadth }_{R}=2 * R_{C} \\
& \text { draft }_{R}=\frac{\pi}{4} R_{C}
\end{aligned}
$$

Type III: rectangular section with the same draft and buoyancy of circular section, but different breadth

$$
\begin{aligned}
& A_{C}=A_{R}=\left(\pi R_{C}{ }^{2}\right) / 2=\text { Breadh }_{R} * \text { Draft }_{R} \\
& \text { draft }_{R}=2 * R_{C} \\
& \text { breadth }_{R}=\frac{\pi}{4} R_{C}
\end{aligned}
$$

As shown in Fig.16 $\mathrm{R}_{c}, \mathrm{~A}_{\mathrm{c}}$, Draft ${ }_{\mathrm{c}}$ and are radius, section area (wet section area), draft and breadth of circular pontoon,

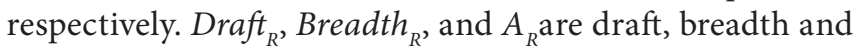
section area of rectangular pontoon, respectively.
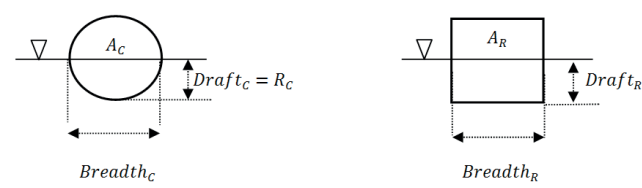

Fig.16 similar rectangular and circular sections parameters 


\section{CALCULATION OF TRANSMISSION COEFFICIENTS FOR A SET OF CIRCULAR AND RECTANGULAR SECTIONS}

For the sake of simplicity, it is assumed that all sections are homogeneous, mass uniformly distributed and center of gravity coincide with center of buoyancy. Among three configuration of mooring line shown in Figure 3, the configuration $\mathrm{C} 1$ is chosen for calculation. For the stiffness matrix of mooring line, coordinate of connection point to breakwater has been modified based on geometry change. The present numerical model has been implemented for 25 circular sections and 75 equivalent similar rectangular sections to obtain transmission coefficient. The specifications of these 100 sections are shown in Table2.

A typical Ct versus $\omega$ is shown in Figure17. This type of Ct behavior is applicable for circular, rectangular and any other sections. It starts with $\mathrm{Ct}=1$ for low frequency, as low as about 2 radian per second, and then starts to decrease. Suddenly, it sharply decreases and reaches to zero for complete reflection condition theatrically. But in fact, a local minimum $\mathrm{Ct}<0.1$ takes at frequency that called LMinF (Fig.17) which is around 3 to 7 radians per second usually. After that, it rises and reaches a local maximum Ct that called LMaxCt at a frequency that called LMaxF (Fig.17).

Tab. 2.Specification of 100 similar circular and rectangular sections

\begin{tabular}{|c|c|c|c|c|c|c|c|}
\hline \multirow[b]{3}{*}{ No. } & \multirow{3}{*}{$\begin{array}{l}\text { Circular } \\
\text { Radius(m) }\end{array}$} & \multirow{2}{*}{\multicolumn{2}{|c|}{$\begin{array}{c}\begin{array}{c}\text { Rectangular Pontoons } \\
\text { Type I }\end{array} \\
\qquad\left\{\begin{array}{c}\text { Breadth }_{\mathrm{R}} \\
\text { Draft }_{\mathrm{R}}=\text { Breadth }_{\mathrm{c}}\end{array}\right.\end{array}$}} & \multirow{2}{*}{\multicolumn{2}{|c|}{$\begin{array}{c}\begin{array}{c}\text { Rectangular Pontoons } \\
\text { Type II }\end{array} \\
\qquad \begin{array}{c}\text { Breadth }_{\mathrm{R}}=\text { Breadth }_{\mathrm{c}} \\
\text { Buoyancy } \mathrm{R}\end{array}=\text { Buoyancy }_{\mathrm{C}}\end{array}$}} & \multirow{2}{*}{\multicolumn{2}{|c|}{$\begin{array}{c}\begin{array}{c}\text { Rectangular Pontoons } \\
\text { Type III }\end{array} \\
\qquad \begin{array}{c}\text { Draft }_{\mathrm{R}}=\text { Draft }_{\mathrm{C}} \\
\text { Buoyancy }_{\mathrm{R}}=\text { Buoyancy }_{\mathrm{C}}\end{array}\end{array}$}} \\
\hline & & & & & & & \\
\hline & & $\operatorname{Breadth}(\mathrm{m})$ & $\operatorname{Draft}(\mathbf{m})$ & $\operatorname{Breadth}(\mathrm{m})$ & $\operatorname{Draft}(\mathbf{m})$ & $\operatorname{Breadth}(\mathrm{m})$ & $\operatorname{Draft}(\mathbf{m})$ \\
\hline 1 & 0.1 & 0.2 & 0.1 & 0.2 & 0.0785 & 0.1571 & 0.1 \\
\hline 2 & 0.125 & 0.25 & 0.125 & 0.25 & 0.0982 & 0.1963 & 0.125 \\
\hline 3 & 0.15 & 0.3 & 0.15 & 0.3 & 0.1178 & 0.2356 & 0.15 \\
\hline 4 & 0.175 & 0.35 & 0.175 & 0.35 & 0.1374 & 0.2749 & 0.175 \\
\hline 5 & 0.2 & 0.4 & 0.2 & 0.4 & 0.1571 & 0.3142 & 0.2 \\
\hline 6 & 0.225 & 0.45 & 0.225 & 0.45 & 0.1767 & 0.3534 & 0.225 \\
\hline 7 & 0.25 & 0.5 & 0.25 & 0.5 & 0.1963 & 0.3927 & 0.25 \\
\hline 8 & 0.275 & 0.55 & 0.275 & 0.55 & 0.216 & 0.432 & 0.275 \\
\hline 9 & 0.3 & 0.6 & 0.3 & 0.6 & 0.2356 & 0.4712 & 0.3 \\
\hline 10 & 0.325 & 0.65 & 0.325 & 0.65 & 0.2553 & 0.5105 & 0.325 \\
\hline 11 & 0.35 & 0.7 & 0.35 & 0.7 & 0.2749 & 0.5498 & 0.35 \\
\hline 12 & 0.375 & 0.75 & 0.375 & 0.75 & 0.2945 & 0.589 & 0.375 \\
\hline 13 & 0.4 & 0.8 & 0.4 & 0.8 & 0.3142 & 0.6283 & 0.4 \\
\hline 14 & 0.425 & 0.85 & 0.425 & 0.85 & 0.3338 & 0.6676 & 0.425 \\
\hline 15 & 0.45 & 0.9 & 0.45 & 0.9 & 0.3534 & 0.7069 & 0.45 \\
\hline 16 & 0.475 & 0.95 & 0.475 & 0.95 & 0.3731 & 0.7461 & 0.475 \\
\hline 17 & 0.5 & 1 & 0.5 & 1 & 0.3927 & 0.7854 & 0.5 \\
\hline 18 & 0.525 & 1.05 & 0.525 & 1.05 & 0.4123 & 0.8247 & 0.525 \\
\hline 19 & 0.55 & 1.1 & 0.55 & 1.1 & 0.432 & 0.8639 & 0.55 \\
\hline 20 & 0.575 & 1.15 & 0.575 & 1.15 & 0.4516 & 0.9032 & 0.575 \\
\hline 21 & 0.6 & 1.2 & 0.6 & 1.2 & 0.4712 & 0.9425 & 0.6 \\
\hline 22 & 0.625 & 1.25 & 0.625 & 1.25 & 0.4909 & 0.9817 & 0.625 \\
\hline 23 & 0.65 & 1.3 & 0.65 & 1.3 & 0.5105 & 1.021 & 0.65 \\
\hline 24 & 0.675 & 1.35 & 0.675 & 1.35 & 0.5301 & 1.0603 & 0.675 \\
\hline 25 & 0.7 & 1.4 & 0.7 & 1.4 & 0.5498 & 1.0996 & 0.7 \\
\hline
\end{tabular}




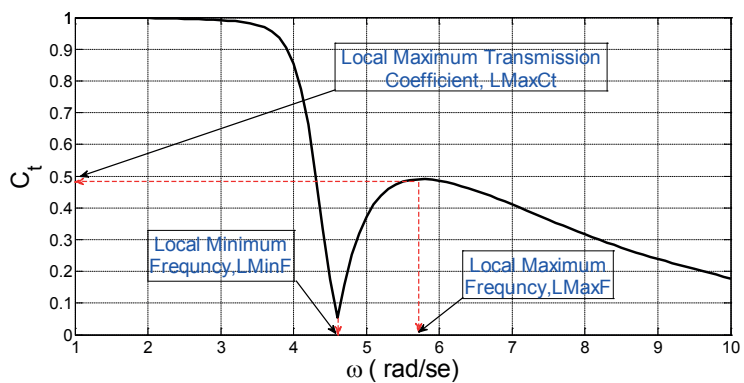

Fig.17. Typical Ct versus $\omega$ and definition of LMinF, LMaxF and LMaxCt

If one could so design a FB for which the working condition is set in the range of LMinF and over, then this kind of FB design has the best transmission condition for the whole operation condition. Certainly, among them, the best FB is one which has the lowest LMaxCt.

The transmission coefficient of circular section and three similar rectangular sections as categorized by types I, II and III (Table 2) versus wave angular frequency, $\omega$, are shown in Figs. 18 to 21.

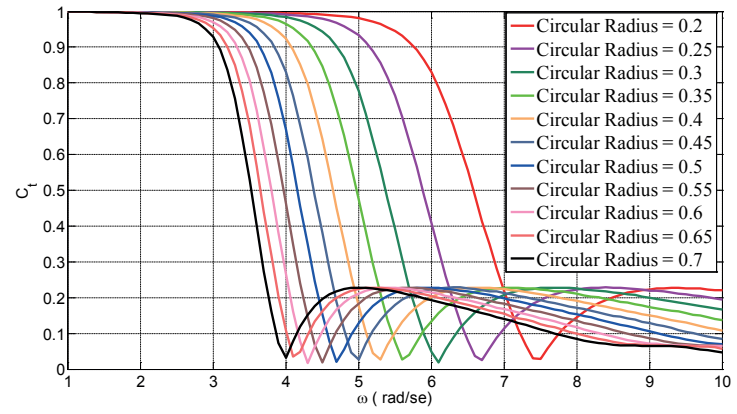

Fig. 18. Ct of circular sections with different radius

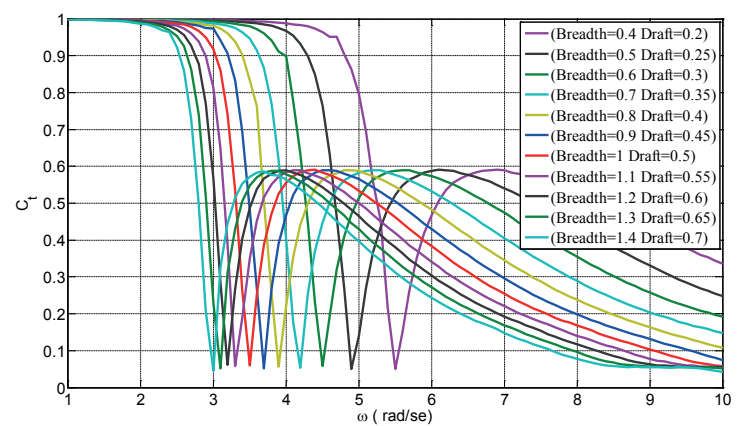

Fig. 19. Ct of rectangular pontoon section, type I

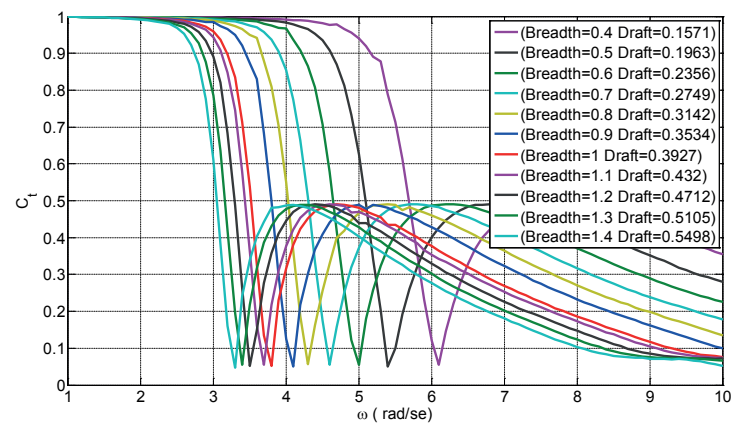

Fig. 20. Ct of rectangular pontoon section, type II

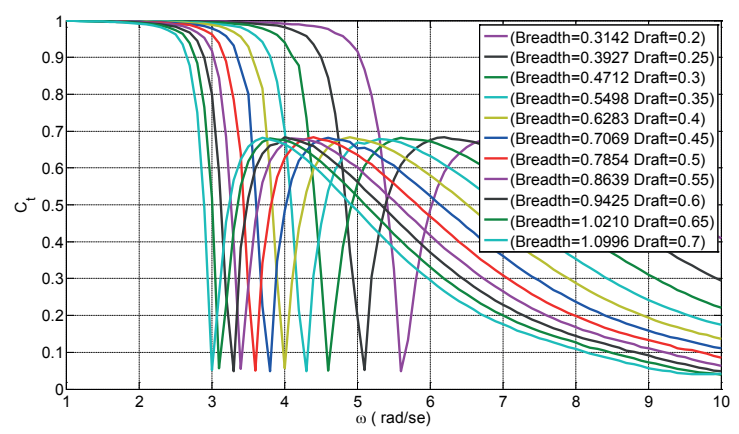

Fig. 21. Ct of rectangular pontoon section, type III

Figure18 depicts transmission coefficient of circular section having radius ranging from 0.2 to 0.7 meter. For all ranges it follows the typical behavior as shown in Figure 17. The LMinF is about 4 to 7.5 radians per second for whole range of circular section radius. However, as circular sections radius increases the LMinF and LMaxF decreases. The LmaxCt is almost constant, 0.22 , for whole range of radius.

The typical behavior of Figure 17 is repeated for the rectangular sections. Having seen in circular section, as the size of rectangular section increases the LMinF and LMaxF are shifting to the lower frequencies. However, LMaxCt is 0.59, 0.49 and 0.68 for Type I, II and III, respectively.

As an example of comparison, Figure 22 presents $\mathrm{Ct}$ comparison of circular section (radius $=0.3 \mathrm{~m}$ ) and three similar rectangular sections. Although, LMaxCt of circular section is smaller than three equivalent rectangular sections however, the LMinF and LMaxF of three rectangular types are smaller than circular section.

An important conclusion of this comparison is that the rectangular section of Type II is more comparable to the circular section than others. The reason of this kind of similarity returns back to the ratio of $\mathrm{B} / \mathrm{D}$. It seems that $\mathrm{B} / \mathrm{D}$ plays an important role which will be discussed in next section. The same behaviors may be seen for other circular section in comparison with similar rectangular sections.

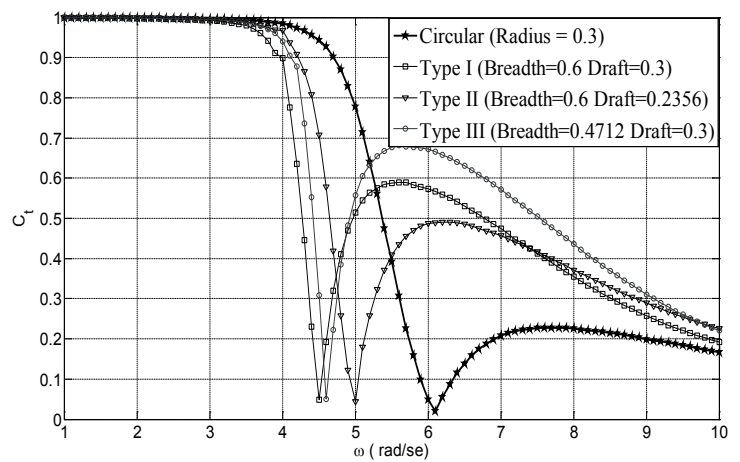

Fig. 22 Ct comparison of circular section (radius=0.3 $\mathrm{m}$ ) and three similar rectangular sections 


\section{DISCUSSIONS AND ANALYSIS}

\section{TYPICAL FB PARAMETRIC STUDY}

Parametric study of FB is classically concerns the Ct versus relative breadth, $B / L$ (breadth to wavelength), relative draft, $D / L$ (draft to wavelength) and normalized frequency, $\omega^{2} B / 2 g$.

Figures 23 to 25 show Ct against $B / L, D / L, \omega^{2} B / 2 g$ for 100 sections (circular and three types of similar rectangular), respectively. The domination of wave length on $\mathrm{Ct}$ as shown in previous Figures, such as Figures 18 to 21 is repeated here.

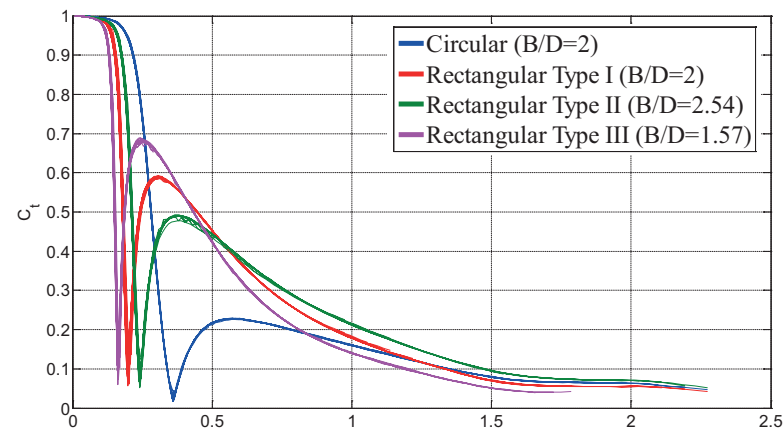

Fig. 23. Ct comparison of circular section and three similar rectangular sections versus relative breadth

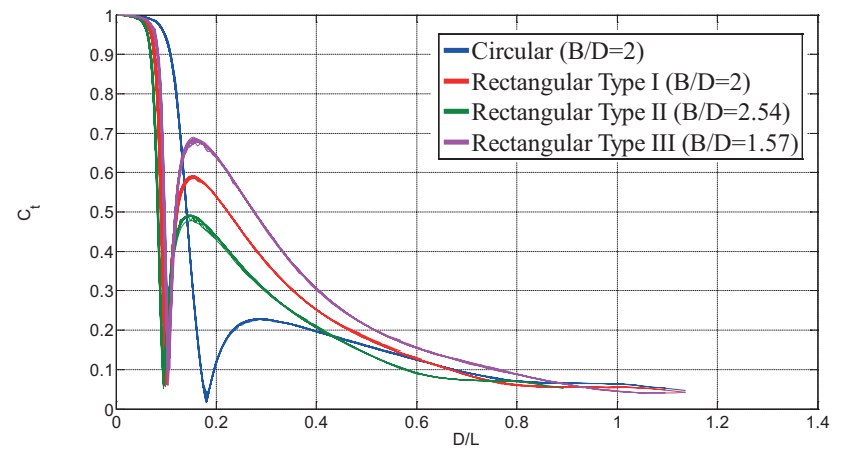

Fig. 24. Ct comparison of circular section and three similar rectangular sections versus relative draft

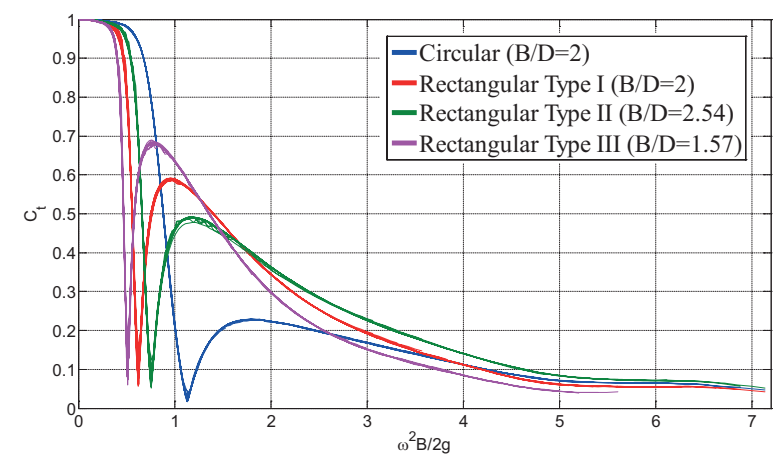

Fig.25. Ct comparison of circular section and three similar rectangular sections versus normalized frequency

\section{CT VERSUS NEW PARAMETER, B/D}

Having considered the LMaxCt for different kind and type of sections, the $B / D$ may be introduced as a new nondimensional parameter. For rectangular sections, $B / D$ is 2 , 2.54 and 1.57 for Type I, II and III, respectively. Furthermore, for circular section the $B / D$ is 2 for all cases as per Table 2 . Additional calculation for LMaxCt of rectangular sections and circular section are performed and depicted in Figure 26. It can be seen that as B/D increases, the LMaxCt sharply decreases for rectangular sections. Anyway, LMaxCt of circular section is unique as $\mathrm{B} / \mathrm{D}$ is unique and smaller than all rectangular sizes.

Actually, a FB is working in a range of wave frequencies mostly between LMinF and LMaxF as well as beyond. So, it is important to have low $\mathrm{Ct}$ for a range of wave frequencies. In Table 3 the average of LmaxCt is shown for all FB as per Table 2. LMaxCt of rectangular are at least twice than circular and it is simply concluded that the circular section has better performance than all equivalent types of rectangular sections.

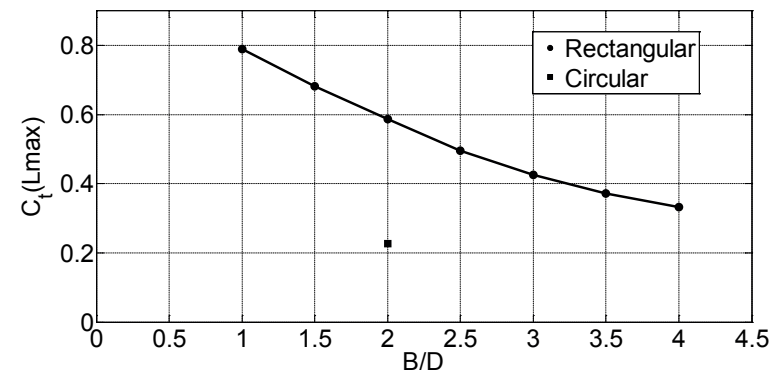

Fig. 26. LMaxCt of rectangular and circular section versus $B / D$

Tab. 3. LMaxCt comparison of circular and rectangular sections

\begin{tabular}{|c|c|}
\hline FB Section & Mean LMaxCt \\
\hline Circular & 0.2274 \\
\hline Rectangular Type I & 0.5865 \\
\hline Rectangular Type II & 0.4883 \\
\hline Rectangular Type III & 0.6778 \\
\hline
\end{tabular}

\section{CONCLUSIONS}

The aim of this study is to compare the performance of circular section and rectangular sections as a breakwater in detail. For this purpose a 2-D computer code based on finite element method has been developed. The code results are validated in comparison with experimental methods where good compliance has been achieved.

A set of 100 breakwater sections, 25 circular sections and 75 equivalent rectangular sections, has been defined and their transmission coefficients are calculated. A comparison is made between the circular section and rectangular sections transmission coefficients. 
Three new points LMinF, LMaxF and LmaxCt defined on Ct versus $\omega$ and a new non-dimensional parameter, $\mathrm{B} / \mathrm{D}$, has been introduced. It has been shown that the LMaxCt of all sections are very dependent to this parameter.

There are some advantages for rectangular and some for circular sections.

LMinF and LMaxF of similar rectangular sections are smaller than circular sections.

LMaxCt of similar rectangular sections are at least twice of circular sections. It means Ct of circular section does not sharply change between LMinF and LMaxF in comparison with rectangular sections.

Generally, the circular sections have shown better performance than the rectangular section in whole range of wave frequencies.

Actually, the decision regarding type of section for $\mathrm{FB}$ not only depends on Ct performance, but also the cost of production is to be considered. However, the application of circular section as FB is not easy to be discarded. Although, rectangular sections are more common for $\mathrm{FB}$, but the results of this study show that possibility of using circular sections must be considered.

\section{REFERENCES}

1. Behzad, M. and Akbari, M., 2007.Experimental investigation on response and efficiency of moored pontoon type floating breakwaters, Iranian Journal of Science \& Technology, Transaction B, Engineering., 31: 95-99

2. Blumberg, G. P. and Cox, R. J., 1998.Floating breakwater physical model testing for marina applications, Bulletin of the Permanent International Association of Navigation Congresses., 63: 5-13

3. Dimer, N., Agnon, Y., and Stiassnie M., 1992.A simplified analytical model for a floating breakwater in water of finite depth, Applied Ocean Research., 14: 33-41.

4. Isaacson, M., Whiteside, N., Gardiner, R. and Hay, D., 1995.Modeling of a circular-section floating breakwater, Canadian Journal of Civil Engineering., 22:714-722

5. Ji, C. Y., Chen, X., Cui, J., Yuan, Z. M. and Incecik, A., 2015. Experimental study of a new type of floating breakwater., Waterway, Port, Coastal, Ocean Eng., 105: 295-303

6. Lee, J. and Cho, W., 2003.Hydrodynamic analysis of wave interactions with a moored floating breakwater using the element-free Galerkin method, Canadian Journal of Civil Engineering., 30(4):720-33.

7. Loukogeorgaki, E. and Angelides, D., 2005.Performance of Moored Floating Breakwaters, International Journal Of Offshore and Polar Engineering., 15: 264-273
8. Loukogeorgaki, E. and Angelides, D., 2005.Stiffness of mooring lines and performance of floating breakwater in three dimensions, Applied Ocean Research., 27: 187-208.

9. Mani, J. S., 1991.Design of Y-frame floating breakwater. Waterway, Port, Coastal, Ocean Eng., 117(2):105-118.

10. Mays, T. W., Plaut, R. H. and Liapis, S., 1998.Threedimensional analysis of submerged moored cylinders used as breakwaters, Waterway, Port, Coastal, Ocean Eng 1998., 26(12):1311-1333

11. McCartney, B. L., 1985.Floating breakwater design. Waterway, Port, Coastal, Ocean Eng., 111(2):304-318.

12. Ozeren, Y., Wren, D. G., Altinakar, M. and Work, P. A., 2011.Experimental Investigation of Cylindrical Floating Breakwater Performance with Various Mooring Configurations, Waterway, Port, Coastal, Ocean Eng., 137(6): 300-399.

13. Sannasiraj, S. A., Sundar, V., and Sundaravadivelu R., 1998. Mooring forces and motion responses of pontoon-type floating breakwaters, Waterway, Port, Coastal, Ocean Eng., 25(1): 27-48.

14. Sawaragi, T., 1995.Coastal Engineering Waves Beaches, Wave-Structure Interactions, Amsterdam: Elsevier

15. Shankar, S., 1998.Performance of twin-pontoon floating breakwaters, University of British Columbia

\section{CONTACT WITH THE AUTHORS}

\section{Seyyed Mohammad Reza Tabatabaei}

e-mail:tabatabai58@aut.ac.ir

Hamid Zeraatgar

e-mail:hamidz@aut.ac.ir

Amirkabir University of Technology

Tehran

IRAN 